\title{
Configurações
}

Revista Ciências Sociais

\section{Ricardo Antunes. Os Sentidos do Trabalho: Ensaio sobre a afirmação e negação do trabalho. Coimbra: CES/Almedina, 2013}

Fabiane Santana Previtali

\section{(2) OpenEdition}

Journals

Edição electrónica

URL: http://journals.openedition.org/configuracoes/2192

DOI: 10.4000/configuracoes. 2192

ISSN: 2182-7419

Editora

Centro de Investigação em Ciências Sociais

Edição impressa

Data de publição: 1 dezembro 2013

Paginação: 241-245

ISBN: 1646-5075

ISSN: 1646-5075

Refêrencia eletrónica

Fabiane Santana Previtali, « Ricardo Antunes. Os Sentidos do Trabalho: Ensaio sobre a afirmação e negação do trabalho. Coimbra: CES/Almedina, 2013 », Configurações [Online], 12 | 2013, posto online no dia 08 outubro 2014, consultado o 21 dezembro 2020. URL : http://journals.openedition.org/ configuracoes/2192; DOI : https://doi.org/10.4000/configuracoes.2192

Este documento foi criado de forma automática no dia 21 dezembro 2020.

(C) CICS 


\title{
Ricardo Antunes. Os Sentidos do Trabalho: Ensaio sobre a afirmação e negação do trabalho. Coimbra: CES/Almedina, 2013
}

\author{
Fabiane Santana Previtali
}

1 Chega a Portugal a obra Os Sentidos do Trabalho: Ensaio sobre a afirmação e negação do trabalho, do renomado sociólogo Ricardo Antunes. Antunes é um autor brasileiro, graduado em Administração Pública pela Faculdade Getúlio Vargas, mestre em Ciência Política pela Universidade Estadual de Campinas (UNICAMP), doutor em Sociologia pela Universidade de São Paulo e livre-docente em Sociologia do Trabalho pela UNICAMP, instituição na qual é atualmente professor titular de Sociologia. $O$ autor é referência internacional no campo da Sociologia do Trabalho com diversas publicações na Argentina, Itália, Inglaterra e agora Portugal.

2 Na obra em questão, publicada originalmente em 1999, após estudos realizados na Universidade de Sussex/Inglaterra, a convite de István Mészáros, Antunes parte de uma densa e rigorosa análise sobre a nova configuração da classe trabalhadora, mais heterogênea e multifacetada, bem como das imbricações entre trabalho produtivo e improdutivo, material e imaterial, para recolocar e dar concretude à tese da centralidade do trabalho e sua importância na sociabilidade humana, uma vez que o trabalho é, segundo o autor, elemento ontologicamente essencial e fundante da existência humana.

o livro está estruturado em onze capítulos, ao longo dos quais Antunes argumenta com vigor acerca da centralidade do trabalho no mundo contemporâneo, tanto no plano teórico, enquanto categoria explicativa da existência humana, como no plano empírico, da práxis. A tese central defendida pelo autor é que, apesar da crise que se instaura na sociedade capitalista, é possível argumentar a favor da "[...] centralidade da categoria trabalho na formação societal contemporânea, contra a desconstrução teórica que foi realizada nos últimos anos" (p. 13). Ao desenvolvê-la, Antunes explicita sua oposição à 
tese habermasiana da ciência como principal força produtiva em detrimento do trabalhovalor.

4 Apoiando-se em Marx, Lukács e Meszáros, o autor argumenta que, na medida em que o capital necessita do trabalho vivo para se reproduzir, não cabe afirmar que é possível uma sociedade capitalista sem exploração do trabalho e fundada na preponderância da ciência como principal força produtiva. Para Antunes, uma coisa é a necessidade do capital em reduzir sua dimensão variável e aumentar a parte constante; outra coisa é imaginar que, eliminando o trabalho vivo, o capital possa continuar se reproduzindo. $O$ autor é enfático ao afirmar que "[...] a tese da eliminação do trabalho abstrato não encontra respaldo teórico e empírico para a sua sustentação nos países capitalistas avançados como os EUA, o Japão, a Alemanha, e muito menos nos países do chamado Terceiro Mundo" (p. 122).

5 A inovação técnica é um estímulo intrínseco ao modo de produção capitalista, pois reduz o tempo de trabalho necessário, assim como o valor da mercadoria e da força de trabalho. Nesse sentido, é preciso ter-se em conta que o desenvolvimento da ciência e da tecnologia é determinado pela lógica de acumulação do capital e não das necessidades humanas. Nas palavras do autor:

“[...] trabalho vivo, em conjunção com ciência e tecnologia, constitui um complexa e contraditória unidade, sob as condições de desenvolvimento capitalista. [...] Liberada pelo capital para expandir-se, mas sendo em última instância prisioneira da necessidade de subordinar-se aos imperativos do processo de criação de valores, a ciência não pode converter-se em principal força produtiva." (p. 122-123)

6 Antunes destaca que o conhecimento social gerado pela ciência tem seu objetivo restringido pela lógica do capital ao mesmo tempo que ocorre a apropriação desigual dos resultados e benefícios da ciência e da tecnologia, bem como do aumento da produtividade do trabalho social. $\mathrm{O}$ autor ressalta que a teoria do valor reconhece o papel crescente da ciência, mas afirma que esta se encontra tolhida em seu desenvolvimento pela base material das relações entre capital e trabalho, a qual se encontra submetida, “[...] não podendo, sob o capital, tornar-se a principal força produtiva no lugar do trabalho" (p. 126).

7 Assim, contrário à ideia de que a classe trabalhadora está no fim, Antunes explica as mudanças no mundo do trabalho como parte do processo de reestruturação produtiva do capital, o qual tem como "dimensão fenomênica" (p. 35) a crise do taylorismo-fordismo e a difusão de novos modelos produtivos, destacando-se o toyotismo, bem como a ascensão do ideário neoliberal. Segundo o autor, a reestruturação produtiva consiste em uma resposta do capital à sua lógica destrutiva e aos seus determinantes estruturais, quais sejam: as taxas decrescentes do lucro, a resistência operária e a própria impossibilidade de controle do capital, enquanto um sistema de metabolismo societal orientado para a expansão e acumulação do capital.

8 De acordo com Antunes, o novo modelo produtivo passa pela maior integração entre trabalho vivo e trabalho morto, assumindo como consequência os seguintes contornos: a) a convergência de trabalho vivo em trabalho morto; b) a redução do trabalho chamado improdutivo, relacionado às atividades de gerência e supervisão; c) a redução dos tempos improdutivos no processo de trabalho; e d) a ampliação do trabalho imaterial, este dotado de maior dimensão intelectual nos setores produtivos e de serviços. Essas tendências se dão de forma diferenciada em função da divisão capitalista do trabalho que assume um caráter desigualmente combinado. 
9 Um dos pontos altos do livro é a exposição, com grande riqueza de detalhes, da reestruturação produtiva na Inglaterra, no bojo das políticas neoliberais e da introdução do toyotismo nos processos de trabalho. Antunes discorre, apoiando-se em densa e rigorosa pesquisa empírica, sobre as lutas de classes naquele país, com movimentos de oposição de grande envergadura, entre os quais a onda de explosões sociais de 1989 e 1990 que atingiu o conservadorismo de Thatcher e possibilitou a vitória de Tony Blair com a chamada "Terceira Via". Esta, por sua vez, configurou-se, de acordo com Antunes, como a preservação do que é fundamental no neoliberalismo, portanto fadada ao fracasso já em seu nascimento.

Na visão de Antunes, a classe trabalhadora que emerge, resultante, simultaneamente, das lutas de classe e da lógica interna do capitalismo global (isto é, da relação entre economia e política), é mais abrangente que a classe trabalhadora de meados do século passado, sendo ainda mais complexa, mais heterogênea e fragmentada que aquela que predominou no período áureo do sistema taylorista-fordista. Discordando daqueles que entendem como classe trabalhadora somente o proletariado industrial e ainda da ideia que reduz o trabalho produtivo exclusivamente ao universo fabril, o autor propõe a noção de classeque-vive-do-trabalho, através da qual busca revigorar o conceito marxista de classe e apreender dialeticamente as particularidades das novas formas sociais de relações laborais.

11 Para Antunes, a classe-que-vive-do-trabalho diz respeito à totalidade de homens e mulheres, produtivos e improdutivos, desprovidos de meios de produção e que são constrangidos a vender sua força de trabalho no campo e na cidade em troca de salário; ou seja: o proletariado industrial e rural, os trabalhadores terceirizados, subcontratados, temporários, os assalariados do setor de serviços, os trabalhadores de telemarketing e call centers, além dos desempregados. 0 autor ressalta que o proletariado industrial é o seu núcleo principal, porque produz diretamente mais-valia. No entanto, estão excluídos gestores do capital e os que vivem de juros e da especulação, os pequenos empresários e a pequena burguesia urbana e rural proprietária, ainda que possam se constituir importantes aliados da classe trabalhadora no campo político.

12 Nesse sentido, Antunes lança o desafio de se compreender o mosaico de formas que configuram a classe trabalhadora atual, considerando sua heterogeneidade e seu caráter polissêmico e multifacetado. $\mathrm{O}$ autor aponta a tendência à redução do proletariado industrial, estável e especializado, que se desenvolveu na vigência do taylorismofordismo, ao mesmo tempo que se expande o trabalho temporário e em tempo parcial num modelo produtivo assentado na integração tecnológica informacional, na desconcentração do espaço produtivo e na horizontalização da produção. Nesse contexto, Antunes chama a atenção para as novas técnicas de gestão da força de trabalho que incluem as células de produção, o trabalho em equipes e em grupos semiautônomos, o trabalho multifuncional, mais qualificado e participativo. Para o autor, a finalidade de tais mudanças é controlar a subjetividade daquele que trabalha com um discurso de envolvimento que, em verdade, é uma participação manipuladora e que preserva, na essência, as condições do trabalho alienado e estranhado. "Quer pelo exercício laborativo manual, quer pelo imaterial, ambos, entretanto, controlados pelo sistema de metabolismo societal do capital, o estranhamento (Entfremdung) do trabalho encontra-se, em sua essência, preservado" (p. 132).

13 Para Antunes, é fundamental a compreensão das formas contemporâneas de agregação do valor-trabalho, uma vez que a mais-valia não é extraída apenas do plano material do 
trabalho, mas também do imaterial, intensificando as condições da exploração da força de trabalho através da redução ou mesmo eliminação do trabalho improdutivo. Porém o autor faz uma ressalva ao argumentar que o trabalho material ainda é predominante, em relação ao imaterial, principalmente quando se faz uma análise do capitalismo em escala global. No campo das relações laborais, o autor afirma a tendência à flexibilização, ao trabalho terceirizado, precário e desregulamentado, com destaque para o aumento do trabalho feminino em diversos países.

Antunes destaca o papel das lutas sociais para a concretização de um processo de emancipação humana, apesar da heterogeneização, complexificação e fragmentação da classe trabalhadora. Argumentando que todas as formas de rebeldia são igualmente importantes, ressalva que, numa sociedade produtora de mercadorias, as revoltas do trabalho assumem um estatuto de centralidade e as lutas ecológicas, assim como o movimento feminista, quando associam suas reivindicações à denúncia da lógica destrutiva do capital, adquirem maior vitalidade.

Ao finalizar a obra, discorrendo sobre a relação entre trabalho e liberdade, Antunes ressalta a necessidade imprescindível de eliminação do trabalho assalariado, do trabalho fetichizado e estranhado e a criação dos indivíduos livremente associados. Mas essa nova ordem social, dotada de sentido dentro e fora do trabalho, encontra-se vinculada à necessidade de eliminar integralmente o capital e o seu sistema de metabolismo social em todas as suas formas. Nas palavras do autor:

Numa forma de sociabilidade superior, o trabalho, ao reestruturar o ser social, terá desestruturado o capital. E nesse mesmo trabalho autodeterminado que tornou sem sentido o capital gerará as condições sociais para o fl orescimento de uma subjetividade autêntica e emancipada, dando um novo sentido ao trabalho. (p. 184)

Fica evidente que a obra Os Sentidos do Trabalho, de Ricardo Antunes, além de representar uma instigante reflexão teórica a qual busca apreender os novos elementos constituintes do metabolismo societal do capital, representa uma contribuição imprescindível a um projeto de construção de uma sociedade para além do trabalho abstrato, portanto fundada numa autêntica liberdade. A sua leitura torna-se, assim, fundamental para todos aqueles comprometidos com um projeto alternativo à lógica capitalista.

\section{AUTOR}

\section{FABIANE SANTANA PREVITALI}

Universidade Federal de Uberlândia, Faculdade de Artes, Filosofia e Ciências Sociais fabianesp@netsite.com.br 